\title{
Chapter 43 \\ Review and New Progress in Wheat Wide Hybridization for Improving the Resistance to Biotic and Abiotic Stresses
}

\author{
Zhen-Sheng Li, Bin Li, Qi Zheng, and Hongwei Li
}

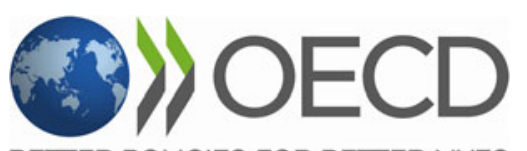

BETTER POLICIES FOR BETTER LIVES

The opinions expressed and arguments employed in this publication are the sole responsibility of the authors and do not necessarily reflect those of the OECD or of the governments of its Member countries.

The Special Session was sponsored by the OECD Co-operative Research Programme on Biological Resource Management for Sustainable Agricultural Systems, whose financial support made it possible for most of the invited speakers to participate in the Special Session.

\begin{abstract}
Since 1956, our group has been working on the wide hybridization between wheat and tall wheatgrass (Thinopyrum ponticum Liu \& Wang, 2n=70). During the past 56 years, we developed a set of partial amphiploids (octoploids), addition lines, substitution lines, translocation lines. A series of wheat cultivars named as Xiaoyan, such as Xiaoyan 4, 5, 6, 54, 60 and 81 were released. They generally have multiple disease resistance and good adaptability to various environments. These traits might derive from tall wheatgrass, especially with respect of resistance to biotic and abiotic stresses. In this paper, we briefly review the history of this study focusing on research background, alien parental selection, establishment of breeding procedure, new germplasms and their application, as well as the newest varieties and their performance to biotic and abiotic stresses.
\end{abstract}

Z.-S. Li $(\bowtie) \cdot$ B. Li $\bullet$ Q. Zheng $\bullet$ H. Li

State Key Laboratory of Plant Cell and Chromosome Engineering, Institute of Genetics and Developmental Biology, Chinese Academy of Sciences, Beijing 100101, China

e-mail: zsli@genetics.ac.cn 
Keywords Wheat breeding • Tall wheatgrass • Translocation

\section{Research Background}

In 1951-1955, our group worked in Beijing engaging in forage research. Because the national development need, we moved to the Northwest, Yangling, Shaanxi in 1956, where is one of the major wheat production area of Huanghuai winter wheat zone in China.

At that time, the local wheat production was just suffering a serious damage caused by stripe rust (Puccinia striiformis $\mathrm{f}$. sp. tritici). Nearly all of the local varieties at that time lost their resistance because of appearance of race, CY1. In general, the disease caused about 20-30 \% yield decline. The total loss in northern China was about 6 Mts each year (Zhuang 2003).

To search a novel way for wheat breeding with persistent resistance to disease, we began the research of wide hybridization between wheat and wild Triticeae species. Twelve grass species were crossed with common wheat. Three of them were successfully hybridized with wheat. They were Agropyron elongatum (Thinopyrum ponticum Liu \& Wang, 2n=70), Agropyron intermedium (Th. intermedium Dewey) and Agropyron trichophorum (Th. trichophorum Lōve). The best one was Th. ponticum based on the performance of their vigorous.

\section{The Establishment of Breeding Procedure}

Common wheat was used as female parent, tall wheatgrass as male parent in cross. The $\mathrm{F}_{1}$ hybrids were very like the tall wheatgrass, but almost all of them were male sterile. Therefore, they were back-crossed with common wheat. $\mathrm{BC}_{1} \mathrm{~F}_{1}$ were becoming wheat-like gradually, but it was not enough, hence they were continually backcrossed with common wheat. The $\mathrm{BC}_{2} \mathrm{~F}_{1}$ individuals were self-crossed. Then, through selection and identification, four types of hybrids were obtained, including partial amphiploids, addition lines, substitution lines, translocation lines (Fig. 43.1; Li et al. 1960, 1962, 1977, 1990; Zhang et al. 1992, 1996).

It is well known that the partial amphiploids usually have middle characteristics between wheat and tall wheatgrass. It could not be used directly in wheat production. Alien addition lines are unstable. Alien substitution lines usually convey no favored characters besides the wanted ones. Therefore, the translocation lines were the final objects in wide hybridization breeding. The translocated small segments can be easily integrated into wheat genome. Hence, on second stage of research work, we focused on the application of translocation lines in wheat breeding. We developed three batches new wheat varieties. Their major characteristics, particularly resistance to biotic and abiotic stresses, planted regions, and the actual effects are introduced below. 


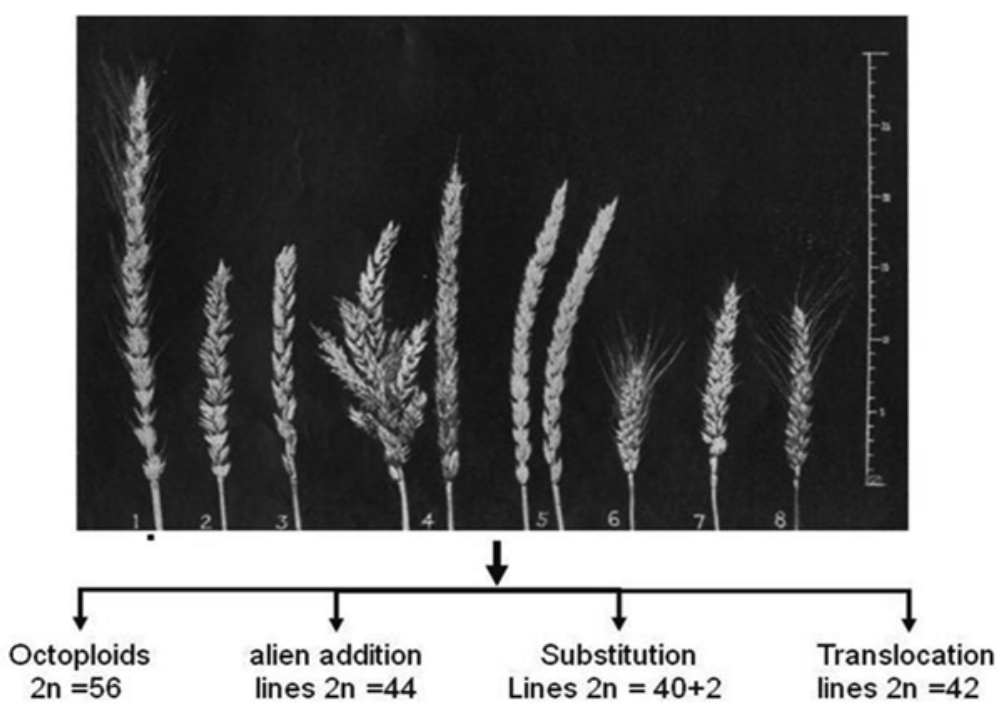

Fig. 43.1 Four types of hybrids derived from cross between wheat and tall wheatgrass

\section{The First Released Variety, Xiaoyan 6}

During early 1980s, we developed the first batch of new wheat varieties, named Xiaoyan 4, 5 and 6, respectively. Xiaoyan 4 and 5 passed the local variety registration and released in Shaanxi province while Xiaoyan 6 passed the national registration and released in 10 provinces ( $\mathrm{Li} 1986)$.

Xiaoyan 6 has durable rust resistance and wide adaptability to various environments. So, it was released in all Huanghuai winter wheat area. Specially, as one of major wheat varieties, Xiaoyan 6 was cultivated for 16 years (1980-1995) in Shaanxi province, accumulatively cultivated about 10 Mha. Xiaoyan 6 was also used as a founder genotype in wheat breeding; more than 50 new varieties were created from its hybrids with other varieties in China. Its derivatives were cultivated more than 20 Mha accumulatively.

\section{Favorable Characters Support the Sustainable Use of Xiaoyan 6 in Production and Breeding}

Broad-Spectrum Resistance to Yellow Rust In 1950s, the yellow rust was frequently epidemic in winter wheat regions of northern China. New rust races created constantly. Up to the 1980s, eight physiological races of yellow rust had been identified. Because of their epidemic, nearly all of wheat varieties at that time lost their 
Fig. 43.2 Reaction of Xiaoyan6 to yellow rust races

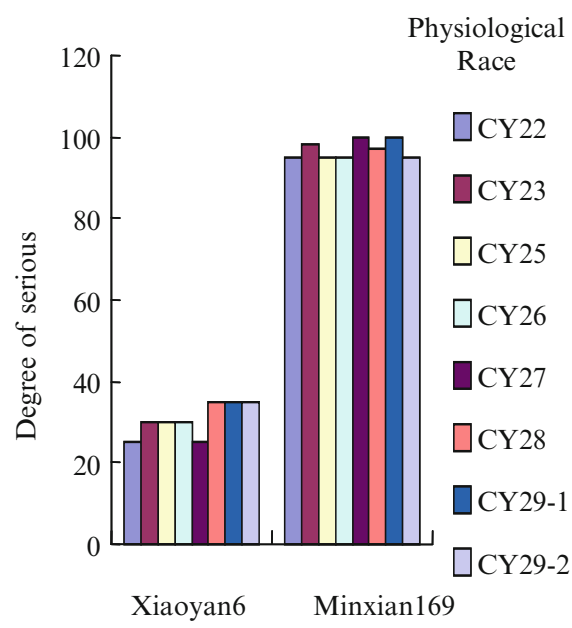

resistance. In general, the disease caused about 20-30 \% loss of yield. In the most serious year, the total loss in northern China was about $6 \mathrm{Mt}$ (Wang et al. 1995).

Artificial infection of 8 yellow rust races (CY22, CY23, CY25, CY26, CY27, CY28, CY29-1 and CY29-2) on Xiaoyan 6 and Mingxian 169 (CK) showed that Xiaoyan 6 resisted to all of the tested epidemic races of yellow rust pathogens during 1980-1990s in North China. Xiaoyan 6 showed characters of a typical slowrusting resistance variety, such as longer latent period, lower disease severity, and less loss of kernel weight (Fig. 43.2; Wang et al. 1996).

Higher and Stable Yield In 1979 trials test, grain yield of Xiaoyan 6 was 5.96 t/ha in average, boosting 15-31.9\% than the control Zhengyin 1, Fengchan 3, and Abodenza in Shaanxi province. In 1980 yield trail, it had 8.5-28 \% more yield than the same controls. So, it easily passed the local and national registration of new cultivars.

Good End Use Quality Xiaoyan 6 has not only higher and stable yield, but also good flour quality. It is suitable for making both bread and Chinese favorable traditional foods, such as Chinese noodles, dumplings, steamed bread, and other traditional cakes (deeply fried dough cake) (Wei et al. 2000; Zhang et al. 2002).

\section{The Second Released Variety, Xiaoyan 54}

In the late 1980s, my group returned to Beijing. The winter temperature in Beijing was lower than Yangling, Shaanxi. In the new environment, new natural variations were found in Xiaoyan 6 population. Through systematical selections, Xiaoyan 54 was bred, which has two important characteristics. First, it was tolerant to drought 
Fig. 43.3 After highlight treatment, the PSII light harvesting protein complexes keep intact in leaves of Xiaoyan 54 , but it was damaged in Jing 411. N normal light, $H$ high light

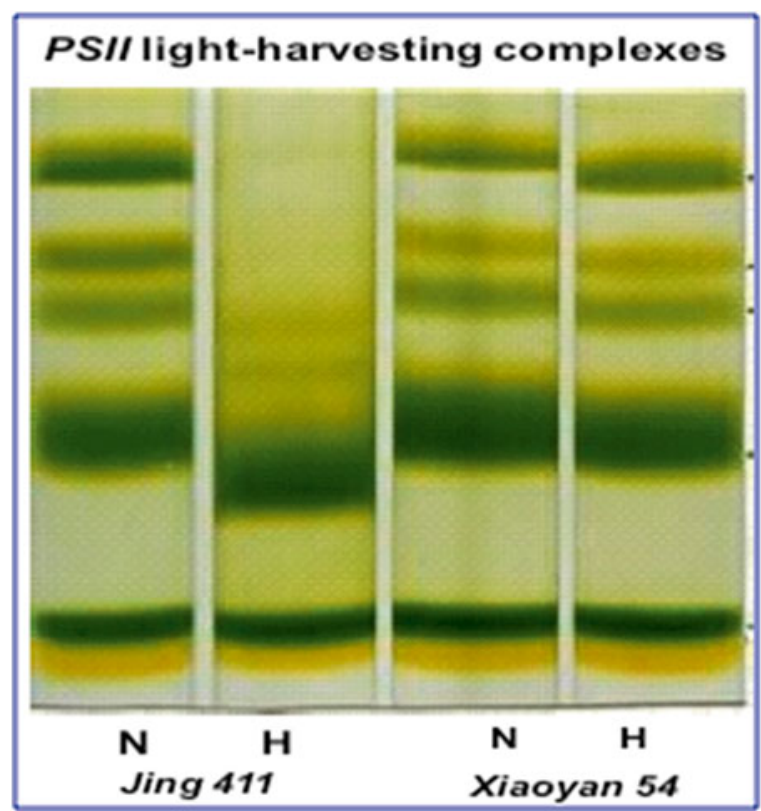

stress in rainfed farming. In 1998-1999, the annual rainfall declined about $40 \%$, only $317 \mathrm{~mm}$ in Guanzhong, Shaanxi province. The grain yield of Xiaoyan 54 was $3.9 \mathrm{t} / \mathrm{ha}$, while the local variety, Shaan 354 was $1.18 \mathrm{t} / \mathrm{ha}$. The WUE of Shaan354 was $0.25 \mathrm{~kg} / \mathrm{mm}$; however, Xiaoyan 54 was up to $0.8 \mathrm{~kg} / \mathrm{mm}$, which is $120 \%$ of the control Shaan354 (provided by Huying Yi, Institute of Soil and Water Conservation, CAS \& MWR).

Second, Xaioyan 54 is tolerant to high light stress (Fig. 43.3, Wang et al. 2000; Yu et al. 2001; Yang et al. 2006). After being stressed by high light, the PSII lightharvesting protein complexes in the leaves of "Xiaoyan 54" retain intact, but in Jing 411 , they were partially damaged.

\section{The Third Released Varieties, Xiaoyan 81 and 60}

In order to meet the development of the Bohai Economic Zone, since 1990s we initiated a new breeding program, salt tolerant wheat breeding. Two new varieties, Xiaoyan 81 and Xiaoyan 60 were bred. The trail experiment showed that Xiaoyan 81 was more tolerant to salt than other varieties (Soil salt total content was almost as high as $0.3 \%$ ) in 2007. At CAS-Nanpi experimental station, Hebei province, the total soil salt content is about $0.2 \%$. Xiaoyan 60 grew much better than the local cultivar, Jimai 32. It also created much higher yield than the CKs in 2 years experiment on the salted land (Table 43.1). 
Table 43.1 Yield performance of Xiaoyan 60 in salted field

\begin{tabular}{|c|c|c|c|c|c|}
\hline \multirow[b]{3}{*}{ Time } & \multirow[b]{3}{*}{ Test site } & \multicolumn{3}{|l|}{ Yield (t/ha) } & \multirow{3}{*}{$\begin{array}{l}\text { Increase } \\
\text { yield (\%) }\end{array}$} \\
\hline & & \multirow[b]{2}{*}{ Xiaoyan 60} & \multirow{2}{*}{\begin{tabular}{|l|} 
Jimai 32 \\
CK1 \\
\end{tabular}} & \multirow{2}{*}{$\begin{array}{l}\text { Jinyin } 32 \\
\text { CK2 }\end{array}$} & \\
\hline & & & & & \\
\hline 2012 & Dry land (Haixing Country) & 3.44 & 2.82 & & 22 \\
\hline 2013 & Dry land (Haixing Country) & 5.06 & 4.11 & & 23 \\
\hline 2013 & Irrigated land (Jinghai Country) & 8.52 & & 6.47 & 27 \\
\hline
\end{tabular}

The breeding success above mentioned made us confidence to further strengthen wild hybridization work. Ten years ago, our group repeated the original crossing work between wheat and tall wheatgrass that $\mathrm{Li}$ and his group did 50 years ago in Northwest Institute of Botany, CAS and used the available partial amphiploids developed in 1960-1980s to create a large number of new translocation lines. The following is some new results in the application of partial amphiploids.

\section{The Application of Partial Amphiploids}

In early 1980s, we developed some partial amphiploids, such as Xiaoyan (XY) 68, 693, 784, 7430, 7431 etc. (Fig. 43.4). Their genomes included three types which are AABBDDEE, AABBDDStSt and AABBDD + (E \& St heterozygous) (Zhang et al. 1996). So, their characteristics are different. For example, in the spring of 2012, we had an opportunity to cooperate with Prof. Zakkie Pretorius, University of the Free, South Africa, to verify resistance of these partial amphiploids to stem rust Ug99. The XY68 and XY7430 showed immune, XY784 performed high resistant to Ug99. The local cultivar Fadkvz was used as control (Fig. 43.5; Table 43.2).

In addition, we also carried out the resistance identification of partial amphiploids to yellow rust, powdery mildew and tolerance to salt. So, my research group repeated the crossing work between wheat and partial amphiploids. Through the radiation treatment to their hybrid offspring, we have obtained more than 200 new translocation lines. Their cytological verification by GISH and FISH were carried out (Fig. 43.6). All of the translocation lines will be used in the multiple character identification and breeding in next stage.

\section{Synthesis and Conclusion}

Looking back 60 years work of wheat wide hybridization breeding, we believe that it has a huge potential and worth continuing, specifically in the aspect of improving wheat wide adaptability to biotic and abiotic stresses. Now climate change has been bringing various disasters on global wheat production. In China, wheat production 


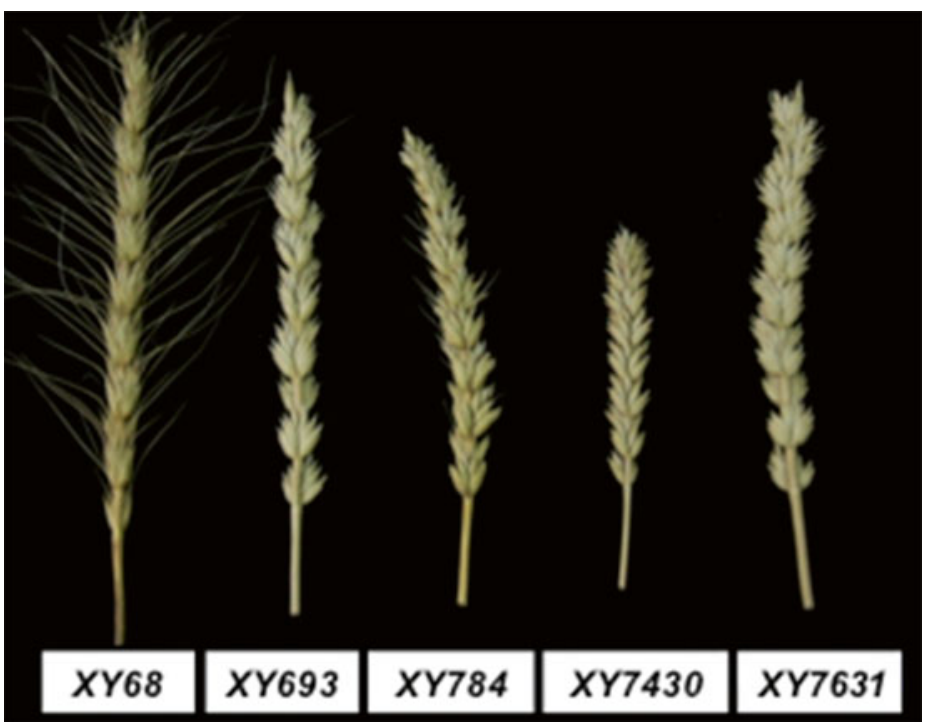

Fig. 43.4 The five partial amphiploids developed in 1980s at Yangling, Shaanxi

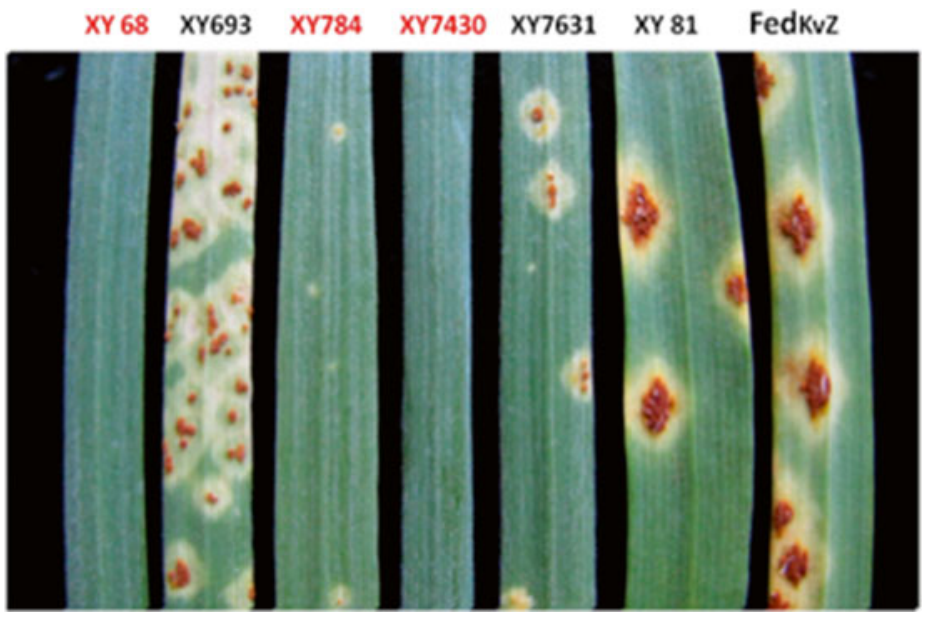

Fig. 43.5 Partial amphiploidsXY68 and XY7430 showed immune, XY784 high resistant to stem rust $U g 99$. The local variety Fadkvz was used as control

Table 43.2 Reaction of wheat-Th. ponticum partial amphiploids to $U g 99$

\begin{tabular}{l|l|l|l|l|l|l|l|l}
\hline & XY68 & XY693 & XY7430 & XY784 & XY7631 & Fed/Kvz & Satu & LCSr24 \\
\hline TTKSF & $;$ & $3 \mathrm{p} 2,1 \mathrm{p} 3$ & $;$ & $; 1=$ & 1 & 1 & $;$ & 2 \\
\hline TTKSP & $;$ & $2 \mathrm{p} 2,2 \mathrm{p} 3$ & $;$ & $; 1=$ & $3 \mathrm{p} 2+, 1 \mathrm{p} 3$ & 1 & $;$ & $3++$ \\
\hline PTKST & $;$ & $3 \mathrm{p} 1,2 \mathrm{p} 2+$ & $;$ & $; 1=$ & $3 \mathrm{p} 1,1 \mathrm{p} 2$ & 4 & $;$ & $3=$ \\
\hline TTKSF+ & $;$ & 1 & $;$ & $; 1=$ & $1 \mathrm{p} 1,2 \mathrm{p} 2$ & 1 & $;$ & 2 \\
\hline
\end{tabular}



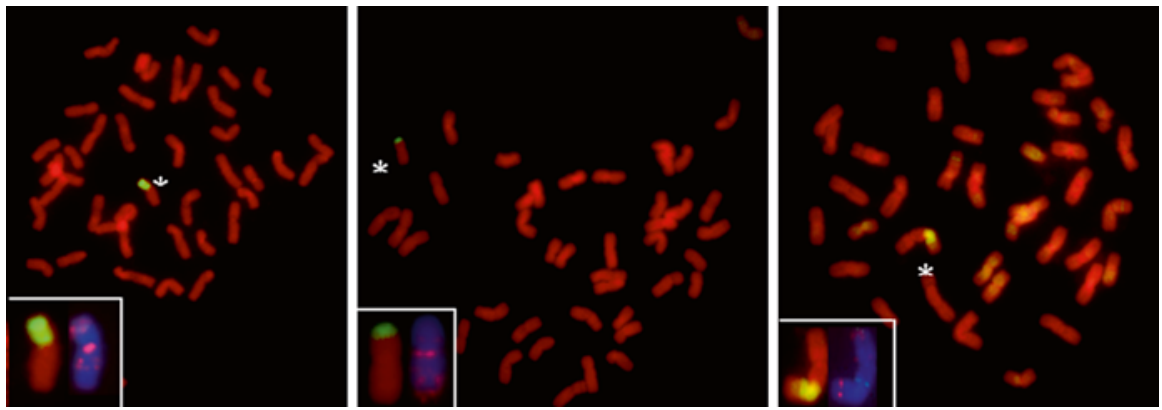

Fig. 43.6 New wheat-Th. ponticum translocation lines; whole arm translocation (left), small fragment translocation (middle) and insertion translocation (right)

is frequently threatened by drought, frost, logging, diseases and pests, which cause unpredictable losses. How to face these challenges?

Based on what we have experienced in the past years, it can be summarized into two strategies. The first is to develop more new germplasms with various genetic backgrounds, for example, using the alien species cross and backcross with common wheat to transfer useful traits to wheat to broaden its genetic basis. The second is to breed wide-adaptability and multi-resistant wheat varieties. The effective methods are establishing the multi-environment field trials and the multi-disease resistance verification facilities. To promote multi-environment verification of disease resistance and adaptability, national and international joint research is a very important strategy. Though the wheat varieties with wide-adaptability and multiresistance are unable to overcome various disasters completely, they can reduce losses of yield and ensure relatively stable harvest.

Acknowledgments We thank S.Y. Chen, S. Rong, W.J. Xue, Z. Li, S.M. Mu, G. C. Zhong, L.Z. Gao, B. Q. Li and X.Y. Zhang in Northwest Institute of Botany, Chinese Academy of Science for their contributions in this work. We also thank Prof. Z. A. Pretorius from the University of the Free State, South Africa, for his help on stem rust test. In addition, we thank Prof. Xueyong Zhang, Institute of Crop Sciences, Chinese Academy of Agricultural Sciences for his presenting of this work on behalf of Prof. Z.S. Li during the 12th International Wheat Genetics Symposium. This work was supported by the grants from the National High-Tech Research and Development Program of China (No. 2011AA1001), the National Natural Science Foundation of China (No. 31171539), and Strategic Priority Research Program of the Chinese Academy of Sciences (No. XDA08000000).

Open Access This chapter is distributed under the terms of the Creative Commons Attribution Noncommercial License, which permits any noncommercial use, distribution, and reproduction in any medium, provided the original author(s) and source are credited. 


\section{References}

Li ZS (1986) Breeding of intergeneric hybridization between Triticum and Agropyron. In: Li Z, Swaminathan M (eds) Proceedings of 1st international symposium chromosome engineering in plants, Xian, pp 179-180

Li ZS, Chen SY, Chen PY et al (1960) Hybridization between wheat and Agropyron (I). Yi Chuan Xue Ji Kan 1:19-39 (in Chinese with English abstract)

Li ZS, Chen SY, Li RL, Liu GJ (1962) Hybridization between wheat and Agropyron (II): study on the sterile and young death of hybrids between wheat and Agropyron. Acta Agron Sin 1:19-26 (in Chinese with English abstract)

Li ZS, Chen SY, Zhang H et al (1977) Hybridization between wheat and Agropyron (IIl): genetic analysis and intergeneric breeding between wheat Agropyron elongatum. Acta Genet Sin 4:283-299 (in Chinese with English abstract)

Li WL, Li ZS, Mu SM (1990) A cytological study of chromosomal structure changes in a common wheat variety, Xiaoyan No. 6. Acta Genet Sin 17:430-437 (in Chinese with English abstract)

Wang FL, Wu LR, Wan AM (1995) Studies on virulence variation of wheat stripe rust population in China. Sci Agric Sin 28:8-14 (in Chinese with English abstract)

Wang BT, Yuan W, Li G, Jin X (1996) Identification of slow-rusting resistance of Xiaoyan No. 6 and ultra-observation on haphae in the host. Acta Botanica Boreali-Occidentalia Sinica 16:432-435 (in Chinese with English abstract)

Wang SW, Xu CC, Bai KZ et al (2000) Comparative study on photo-inhibition between two wheat genotypes. Acta Bot Sin 42:1300-1303 (in Chinese with English abstract)

Wei YM, Zhang GQ, Ouyang SH et al (2000) Aspect and problem on quality improvement $t$ of wheat variety in Guanzhong plain of Shaanxi Province. J Triticeae Crops 20:3-9 (in Chinese with English abstract)

Yang XH, Chen XY, Ge QY et al (2006) Tolerance of photosynthesis to photo-inhibition, high temperature and drought stress in flag leaves of wheat: a comparison between a hybrid line and its parents grown under field conditions. Plant Sci 171:389-397

Yu F, Tang CQ, Xin YY, Pang DC et al (2001) Comparative spectroscopic studies on the photoinhibition process in photosystem I complex from two wheat cultivars. Acta Bot Sin 43:12431249 (in Chinese with English abstract)

Zhang XY, Li ZS, Chen SY (1992) Production and identification of three 4Ag (4D) substitution lines of Triticum aestivum-Agropyron: relative transmission rate of alien chromosomes. Theor Appl Genet 83:707-714

Zhang XY, Dong YS, Wang RRC (1996) Characterization of genomes and chromosomes in partial amphiploids of the hybrid Triticum aestivum $\times$ Thinopyrum ponticum by in situ hybridization, isozyme analysis and RAPD. Genome 39:1062-1071

Zhang XY, Dong YC, You GX et al (2002) Allelic variation of Glu-A1, Glu-B1, Glu-D1 in Chinese released wheat varieties in the last 50 years. Agric Sci China 1:36-44

Zhuang QS (2003) Chinese wheat improvement and pedigree analysis. China Agricultural Publishing House, Beijing 